\title{
A poesia de Manuel Bandeira: a crítica de Mário de Andrade e Sérgio Buarque de Holanda ${ }^{1}$
} RICARDO GAIOTTO DE MORAES I

$\mathrm{N}$ A PRIMEIRA carta que Manuel Bandeira enviou a Mário de Andrade, em 25.5.1922, o autor de "Os sapos" confessa saudades do poema “Oratório" ao poeta que ainda publicaria Pauliceia desvairada. Conta que o endereço do remetente fora dado, "um dia destes", por um rapaz "com aquele ar metálico e laminado, aquele ar que faz compreender de chofre a pintura moderna" (Moraes, 2001, p.59-60). A menção ao poema de Mário de Andrade e o envio de Carnaval (livro de Manuel Bandeira, publicado em 1919) iniciam no diálogo epistolar as longas discussões sobre o fazer poético. Em resposta, Mário agradece o livro, "um clarim de era nova", admirando o poema "Os sapos", que considera um "dos maiores de nossa poesia”, e fazendo ressalva ao “Debussy", “esplêndido em fatura", [... "mas a fatura pouco" lhe interessaria (ibidem, p.62).

Apesar do diálogo constante entre os dois autores, que essa primeira carta insinua, e das inúmeras referências a Manuel Bandeira em artigos e cartas a outros correspondentes, no vasto conjunto de textos de crítica literária de Mário de Andrade, há apenas um ensaio de maior fôlego dedicado ao poeta. Trata-se de "Manuel Bandeira", publicado na Revista do Brasil, de novembro de 1924, cujo foco era Poesias, reunião de A cinza das horas, Ritmo dissoluto e Carnaval, os três livros lançados anteriormente pelo poeta. Mesmo assim, o artigo foi preterido por Mário de Andrade, que o excluiu do volume Aspectos da literatura brasileira (1943), à revelia do próprio Bandeira. ${ }^{2}$

Ainda que não tenha ganhado edição em livro, o artigo de Mário de Andrade repercutiu em uma resenha sobre Poesias, assinada por Prudente de Moraes, neto, e Sérgio Buarque de Holanda - aquele rapaz com ar "metálico e laminado" da primeira carta de Bandeira - publicada na revista Estética, no volume de janeiro-março de 1925. O diálogo estabelecido, dessa vez entre os textos de crítica de Sérgio Buarque e Mário de Andrade, remonta à data anterior, uma vez que já, em fevereiro 1922, Sérgio Buarque publicara, nas páginas da revista Fon-Fon, um artigo sobre Carnaval, de Manuel Bandeira.

Nesse artigo, o autor aproximava os poemas de Carnaval, de Manuel Bandeira, aos do vanguardista Aldo Palazzeschi, mas ressaltando a melancolia como traço de “originalidade" (Holanda, 1996a, p.142). Manuel Bandeira con- 
seguiria posição “entre os verdadeiros autores”, porque muitos de seus poemas só poderiam "ser escritos" por ele e "por ninguém mais", devido a aspectos como o "verso livre" que fugiria a todas "as regras consuetudinárias" (ibidem, p.143). O traço de originalidade, apontado por Sérgio Buarque de Holanda, terá algum eco no artigo de Mário de Andrade, uma vez que, no artigo da $R e^{-}$ vista do Brasil, ele destacará a sinceridade como valor do "poeta que, graças a Deus! é sincero" (Andrade, 1924, p.220).

Atribuir valor positivo à sinceridade do poeta não é um critério exclusivo dos críticos mencionados. Susan Rosembaum (2007, p.16) afirma que, no momento em que o poeta se liberta do mecenato e sua poesia, cuja circulação passa a ser cada vez mais regulamentada pelas leis de direitos autorais, se transforma em comódite, a lírica passaria a ser reconhecida, então, como o espaço em que persona e autor se encontram. Ainda para a autora, ao mesmo tempo em que a busca da sinceridade tanto pelos leitores quanto pelo próprio poeta, a partir pelo menos do romantismo, a lírica parece se estabelecer como um lugar em que a produção artística está à salva das regras do mercado, levando ao desenvolvimento de uma "retórica da sinceridade". Somente assim o poeta poderia estabelecer um contrato de confiança com o público avesso à literatura de massa que se desenvolveria tanto no tema quanto na forma (ibidem, p.13).

Tanto o traço de originalidade, apontado por Sérgio Buarque de Holanda, quanto o de sinceridade, apontado por Mário de Andrade, são categorias que aproximam o julgamento dos dois autores. Se em um plano mais imediato, a "originalidade" parece se relacionar à constituição do estilo pessoal, e a "sinceridade" àquilo que Lionel Trilling (2014, p.12) classifica como congruência entre declaração e sentimento real; em um plano mais profundo, que leva em consideração as acepções críticas de Mário de Andrade e Sérgio Buarque, o conceito de sinceridade (mais que o de originalidade) é mais complexo e parece se relacionar a uma formulação moral do artista diante do próprio fazer poético. Tal postura parece convergir não apenas para o julgamento dos artistas criticados, mas, no caso de Mário de Andrade, como justificativa para a própria trajetória artística, e, para Sérgio Buarque, reverbera na forma como estabelece a visão sobre a formação do homem brasileiro em seu ensaio histórico.

Tendo como foco os textos sobre Manuel Bandeira, este artigo visa analisar os desdobramentos da noção de sinceridade que circulam como argumentos em textos ensaísticos de Sérgio Buarque de Holanda e Mário de Andrade. No caso deste, a busca pela sinceridade parece dialogar com as reflexões sobre a técnica da poesia desenvolvidas sistematicamente em "O artista e o artesão"; no caso daquele, parece figurar como um dos combustíveis para a revolução contra a "cordialidade" brasileira, conforme definida em Raizes do Brasil.

Como a análise deste artigo abrange um período bastante longo na crítica de Mário de Andrade e Sérgio Buarque de Holanda, do início dos anos 1920 
ao início dos 1940, é necessário ponderar que, para além do amadurecimento intelectual dos dois autores, há, nas disputas do campo literário, variações de posições ocupadas que também são importantes na compreensão dos conceitos mobilizados nos textos. Assim, no primeiro artigo, em 1922, sobre "Manuel Bandeira", a abordagem do jovem crítico Sérgio Buarque de Holanda é entusiasmada. Primeiramente, aproxima os poemas do segundo livro do poeta, Carnaval, aos do futurista Palazzeschi por partirem da mesma concepção de "uma poesia compreendida como simples capricho, como mera efusão de um estado lírico qualquer" (Holanda, 1996a, p.142). Mas, ao mesmo tempo, reitera a originalidade, destacando que há uma melancolia, inexistente no gesto do clown do poeta italiano. Assim, de acordo com o crítico, os poemas de Manuel Bandeira somente poderiam "ser escritos por ele e por ninguém mais" e a originalidade que é a expressão sincera do poeta, o elevaria à categoria dos "verdadeiros autores" (ibidem, p.143). É esse "verdadeiro autor" a quem caberia a posição de iniciador da poesia modernista no Brasil, ele teria dado o primeiro golpe na poesia feita a partir de modelos do passado.

O texto não esconde o entusiasmo de Sérgio Buarque de Holanda pelos "futuristas de São Paulo", cuja revista, Klaxon, representava no Rio de Janeiro. O movimento do artigo reitera uma contradição latente nos artigos iniciais dos modernistas e explícita nos ataques que recebiam pelos jornais: o "golpe no passadismo", ou seja, a crítica à poesia brasileira anterior à eclosão da "Semana de Arte Moderna" justificava-se pela busca de uma expressão nova e original, mais sincera que os poemas dos parnasianos por não aproveitar, como esses, convenções determinadas pela literatura produzida fora do país. No entanto, o próprio modernismo, se identificado às vanguardas históricas, poderia ser acusado de falsificação. Por isso, e também por discordâncias com pontos do programa, Mário de Andrade, na crítica e mesmo em Pauliceia desvairada, apenas insinuava a aproximação com o futurismo. ${ }^{3}$

Por ocasião da publicação de Poesias, livro que compila $A$ cinza das horas, Carnaval e Ritmo dissoluto, em 1924, já após a Semana de Arte Moderna, Mário de Andrade lança um artigo sobre Manuel Bandeira. O ritmo do artigo é marcado pela relação entre a personalidade de Manuel Bandeira e as posições que a persona assumiria em relação ao que se passa no mundo. A tuberculose teria marcado fatalmente o poeta fazendo que sua poesia mudasse de ângulo: em vez de um "observador dentro da vida" passara a um "observador contemplativo". No entanto, essa natureza contemplativa seria quebrada em "Carnaval", assim, o poeta:

De primeiro esteve em casa ouvindo contar pelas visitas o que se passava lá fora: Cinza das horas. Ao chegar o reinado de Momo se pintou e saiu. Três dias de forrobodó grosso: Carnaval. Creio que se convenceu de que assim não se divertia. Voltou pra casa. Mas não escutou mais as conversas das visitas. Abriu a janela e assuntou: Ritmo dissoluto. (Andrade, 1924, p.216) 
Essa mudança de ângulo de Carnaval teria permitido, no entanto, que o poeta, ao se misturar com a multidão, pudesse encontrar-se melhor consigo mesmo. Tal atitude seria perceptível na construção de uma identidade poética própria. Em A cinza das horas, Mário de Andrade reconhece nos procedimentos poéticos ainda uma tentativa de treino:

A Cinza das horas não é de Manuel Bandeira. Qualquer poeta bonzinho escreveria esses versos. O convencionalismo domina. Manuel está se procurando nos livros dos outros. Engraçado isso! (ibidem, p.218)

Somente com Carnaval é que Manuel Bandeira haveria encontrado sua própria poesia. A "banalidade banal" dos poemas do primeiro livro teriam se transformado na "vulgaridade sutil" do segundo, o respeito aos temas poéticos convencionais do primeiro na "destruição do assunto poético, moderna conquista do lirismo"! (ibidem, p.218). O Carnaval teria marcado, na poesia de Manuel Bandeira, um momento de "comoção realizada". Em Ritmo dissoluto, o poeta voltaria a seu estado contemplativo, num livro de maior unidade e plenitude psicológica, em que, em vez da "comoção realizada" do segundo livro, seria possível flagrar uma "objetivação formal mais moderna".

Mesmo que o crítico aponte pequenos defeitos nos livros, como a reincidência por meio de diminutivos de tudo o que é amado, Mário de Andrade considera, como grande valor, a busca pela expressão poética que fosse mais coerente à personalidade de Manuel Bandeira, na busca por uma plenitude psicológica. A imagem do poeta que precisa defrontar a multidão de vários ângulos diferentes é recorrente e costuma marcar o embate entre a individualidade e o movimento das massas, como se o próprio movimento fosse um símbolo do lugar da poesia às margens da lógica do capitalismo e do mercado (Rosenbaum, 2007 , p.40). Essa sinceridade seria notada pelo crítico também na liberdade formal que Manuel Bandeira adotara, passando, por exemplo, do decassílabo ao verso livre sem se importar com as vaias da crítica. A elaboração da poesia como busca de uma plenitude psicológica parece, nesse caso, comtemplar a noção um conceito expandido da noção de sinceridade, justamente porque representa também uma tomada de posição moral representada pela recusa a seguir uma forma poética já estabelecida. Caberia perguntar qual a função do crítico diante da admissão dessa fatal busca de si mesmo do poeta, afinal como intuir a coerência sincera entre elaboração poética e personalidade.

É necessário também apontar que o substantivo "sinceridade", seus adjetivo e advérbio cognatos, "sincero" e "sinceramente", nem sempre são utilizados por Mário de Andrade no sentido expandindo, de abrangência moral, que the atribuímos. Algumas vezes sofre variações. É possível, por exemplo, observar que, próximo à Semana de Arte Moderna, o termo é utilizado como sinônimo de liberdade. Ainda na revista Klaxon, designa a criação de uma consciência singular, o que definiria a arte: "A sinceridade em arte não consiste em reproduzir, senão em criar. O seu princípio gerador é a 'consciência singular', pelo qual 
um homem é verdadeiramente digno se ser chamado poeta - isto é: criador" (Andrade, 1922, p.16). Nesse caso, a "sinceridade" estaria muito próxima ao conceito de "originalidade" estrondeado por Sérgio Buarque no primeiro artigo sobre Manuel Bandeira.

Pensando no diálogo da crítica de Mário de Andrade, Sérgio Buarque de Holanda e, incidentalmente, Prudente de Moraes, neto, ${ }^{4}$ este último assina na revista Estética, em 1925, um artigo intitulado "Sobre a sinceridade" bastante esclarecedor. Comentando um artigo de Benjamin Crémieux, na Nouvelle Revue Française, Prudente de Moraes, neto, discorda da conclusão do autor segundo a qual o escritor estaria livre do "terror de ser insincero" devido à impossibilidade de existir uma "imaginação que antes não tenha estado no inconsciente" (Moraes Neto, 1925, p.159), pois se era verdade que tudo o que estivesse na imaginação estaria no inconsciente, nem tudo que estivesse no inconsciente chegaria à imaginação. Seria necessário, portanto, um esforço do artista para trazer à tona mesmo aquilo que fosse censurável diante da sociedade. Assim, ao artista, caberia lutar contra a censura tortuosamente para produzir arte sincera; preocupando-se com a própria vitória pessoal diante da censura, seria constituída assim uma "sinceridade terapêutica" (ibidem, p.161). Nesse caso, o artista evitaria também fazer uma obra cujo principal objetivo fosse agradar ao público. ${ }^{5}$ Seria função da crítica determinar se o artista agrada ao outro, e o julgamento desta estaria na observação do "grau de originalidade" (ibidem, p.162).

Já na crítica mais madura de Mário de Andrade, no final da década de 1930, a palavra "sinceridade", e suas derivações, é utilizada mais frequentemente como sinônimo de "espontaneidade". Tal escolha parece relacionada à necessidade de reafirmar que, apesar de partir de um impulso espontâneo, uma intuição, o artista deveria se preocupar com a forma. Descrevendo a eloquência do narrador de Genolino Amado, em Um olhar sobre a vida, considera que há um "tom de sinceridade", em seguida, corrige, "de espontaneidade" (Andrade, 1993. p.142). Sobre a poesia de Murilo Mendes, Mário de Andrade afirma:

O sr. Murilo Mendes volta estranhamente ao rapsodismo das rezas inventadas, das declarações improvisadas, dos apelos e das apóstrofes irrompidas. Daí um vigor virulento, um tom de sinceridade, ou melhor, de espontaneidade, de uma força, de uma exatidão magníficas. Mas me parece uma grande lição que não deve ser seguida. Porque poesia não é apenas uma essência de assunto. Porque poesia não é apenas lirismo. Porque a poesia não pode ficar nisso. (Andrade, 1993, p.22)

Nesse caso, a sinceridade, também sinônimo de “espontaneidade", estaria no momento intuitivo em que a poesia se formaria como lirismo, o primeiro passo para a criação poética. O dado notável é que, se para Murilo Mendes, essa espontaneidade produziria boa poesia, não seria uma lição a ser seguida. Essa reprimenda é coerente a uma das batalhas assumidas por Mário de Andrade no rodapé "Vida Literária", qual seja, a insistência na necessidade do conhecimento 
e prática do artesanato poético. ${ }^{6}$ Seguindo essa preocupação, Mário de Andrade, na correspondência com Fernando Sabino, já em tempo posterior à participação como crítico do Diário de Notícias, ataca a sinceridade, sinônimo de espontaneidade:

Você, por favor, nunca venha me argumentando com as palavras "espontaneidade" e "sinceridade", tenho verdadeiro horror delas. É a vaidade e também a desonestidade do artista que as inventou. É a eterna e repulsiva confusão entre o artista e a obra-de-arte que lhes dá uma aparência falsa de legitimidade. Pra obra-de-arte, a sinceridade, a espontaneidade do artista não tem significação nenhuma. (Andrade, 1993, p.24)

A sinceridade como espontaneidade disfarçaria o que é artesanato, na obra de arte, e também a obrigação do artista de vagarosamente pensar sobre sua própria criação. $\mathrm{O}$ verdadeiro artista, portanto, seria aquele que tentaria, por meio da técnica pessoal, atingir uma verdade mais universal que apenas sua espontaneidade. $\mathrm{O}$ artista deveria, no estágio de autocrítica, "estar sinceramente entregue ao pensamento do seu assunto, a tomar notas de frase, de traços psicológicos, de formas, de ideias o vai predispondo psicologicamente para o ato de criação" (ibidem, p.25). ${ }^{7}$

Retornando ao artigo de Mário de Andrade, de 1924, sobre o autor de Poesias, seria possível afirmar que a sinceridade de Manuel Bandeira se confirmaria tanto pela convergência entre o poeta que busca sua identidade a partir da convivência com o outro quanto pela escolha da forma poética e do experimentalismo formal. A fatalidade do experimentalismo do poeta, que não se conformaria nem à forma tradicional nem à vanguarda, seria também prova da preocupação de Manuel Bandeira para com o artesanato da poesia.

Em resenha publicada na revista Estética, assinada por Sérgio Buarque de Holanda e Prudente de Moraes, neto, o livro Poemas, de Manuel Bandeira, também é considerado a partir de uma curva natural que descreve a evolução do poeta (Holanda, 1996a, p.207). No entanto destaca-se, como marca dos três momentos poéticos diferentes dos três livros, a inocência, característica que também remeteria à noção de sinceridade. Assim, em Cinza das horas, seria perceptível "exaltações líricas" que "mal disfarçam a inocência", mas também uma exaltação ao "mau gênio da vida" que acometera profundamente o poeta. Carnaval apresentaria libertação em relação à afinidade com alguns poetas de "furor místico", mas o carnaval seria "motivo quase forçado e, apesar do clima de alegria dionisíaca, o poeta ainda permaneceria melancólico e "O riso ainda não" passaria "de um disfarce" (Holanda, 1996a, p.208). No Ritmo dissoluto, Manuel Bandeira "se aproxima de uma tendência inicial procurando o paraíso perdido nas "naturezas primitivas" (ibidem, p.209). Portanto, mesmo que os temas abordados na resenha sejam outros, é possível verificar, como na crítica anterior de Mário de Andrade, Carnaval, como um momento de extravasamento diferente da contemplação do primeiro e do terceiro livros. 


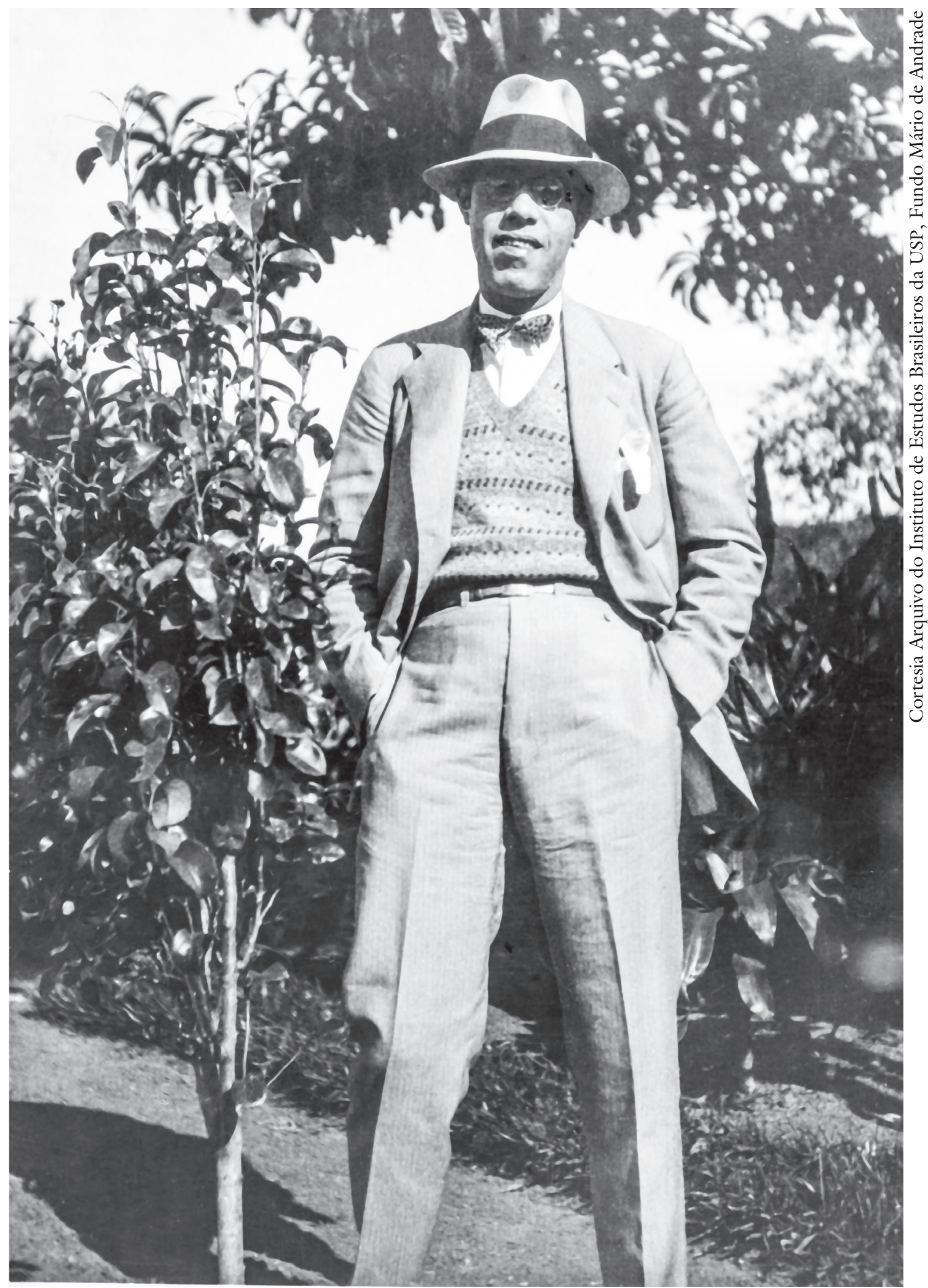

Mário de Andrade em São Paulo, 1929. 
Se na década de 1920, fase de consolidação do lugar ocupado pelos artistas provenientes da Semana de 1922, Manuel Bandeira parece ser tomado como um poeta modelo para as propostas modernistas, tanto pela experimentação formal quanto pela coerência dessa e da personalidade do poeta; na década de 1940, um ponto que parece aproximar as críticas de Mário de Andrade e Sérgio Buarque de Holanda é a análise do próprio movimento modernista, impulsionados pela maturidade, mas sobretudo pelos questionamentos à eficácia das propostas da Semana de Arte Moderna feita em diversas frentes. Por isso, os artigos dos dois autores sobre contemporâneos da Semana de 1922 acabam assumindo, por vezes, um tom de homenagem; mas podem indicar, na descrição dos procedimentos literários, categorias que definiriam aquilo que, para os dois críticos, poderia ser considerado uma postura artística sincera.

Assim, a coerência da obra de Manuel Bandeira será observada por Sérgio Buarque de Holanda no artigo "Poesias completas de Manuel Bandeira", de 1940. Nele, destaca a maneira como essa poesia, apesar de representar uma "voz dissonante" (Holanda, 1996a, p.276) em relação a seus contemporâneos, apresentaria uma profunda coerência, sendo possível já, a partir de Cinza das Horas, contemplar sua unidade, ainda que os procedimentos poéticos fossem diversos. Mesmo após o contato com o simbolismo ou com os modernistas de primeira hora, sua obra não seguiria cegamente nem essa, nem qualquer escola.

Para provar a hipótese da dissonância da poesia de Manuel Bandeira, Sérgio Buarque de Holanda compara-o a contemporâneos como Ronald de Carvalho, cuja poesia seria marcada pela "estilização", ou seja, em suas descrições, a natureza apareceria domesticada, como se estivesse posando diante de "um fotógrafo". Em Manuel Bandeira, mesmo quando o tema era descritivo, a combinação imprevista e particular das imagens daria às cenas um caráter mais invocativo que descritivo. Assim, as descrições de natureza não se limitariam ao pitoresco e, de acordo com depoimento do próprio poeta, expressariam, das "coisas brasileiras", aquilo que "há nelas de mais profundo, isto é, de mais cotidiano" (Holanda, 1996a, p.281). Ao mesmo tempo que marca a particularidade de Manuel Bandeira, a apreciação sugere como tema o problema da representação.

Ao se afastar da "estilização" da natureza e de padrões rígidos de escolas literárias ou de "modismos", Manuel Bandeira desenvolveria sua identidade poética. Em outras palavras, apresentaria uma poesia marcada pelo cultivo pessoal e da técnica não só pela intensidade poética com a qual conseguiria singularizar os ambientes descritos, mas também pela profusão de ritmos e metros com que conseguiria lidar, sem parecer que o ecletismo seria fruto de falta de "princípio criador" ou "coerência". Para Sérgio Buarque, tudo o que Bandeira escreveu revelaria "uma estudiosa aplicação aos mais complicados problemas de técnica do verso" (Holanda, 1996a, p.281).

Se no artigo de 1925, na revista Estética, os ecos do artigo de Mário de Andrade pareciam lastrear as escolhas moralmente sinceras de Manuel Bandeira, 
nesse artigo publicado pelo crítico responsável pela coluna "Vida Literária", Sérgio Buarque de Holanda, no Diário de Notícias apresenta como lastro o raciocínio desenvolvido no Raizes do Brasil, ${ }^{8}$ cuja primeira edição é de 1936. Tal relação parece se aproximar à medida que o autor descreve a preocupação de Bandeira com o artesanato e com a experimentação estética sincera e desinteressada. Assim, o poeta se oporia àquilo que seria a normalidade na poesia brasileira, conforme afirma em um texto de 1948: "Sabemos que no Brasil a deliberação paciente, o trabalho pertinaz e penoso, sem perspectiva de pronto êxito, nunca tiveram suficiente prestígio para se erigirem em virtudes 'poéticas"” (Holanda, 1996b, p.39).

Em Raizes do Brasil, Sérgio Buarque de Holanda desenvolve as vicissitudes desse comportamento avesso, ao que vimos, nesse artigo, definindo como sinceridade. Nesse ensaio o enunciador, dedicado a traçar a raiz portuguesa do caráter brasileiro, mas, ao mesmo tempo, empenhado em denunciar as nuances fundadoras da nacionalidade responsáveis pela impossibilidade de uma revolução, lega à colonização portuguesa tanto a habilidade em conformar colonizador, colonizados, escravos e terra, quanto a violência tanto da formação do brasileiro típico, o homem cordial.

Assim como, na visão de Sérgio Buarque de Holanda, a violência da colonização portuguesa fora disfarçada por certa malemolência resultante do espírito do aventureiro que prefere mirar nos fins (no enriquecimento à custa de um aproveitamento que beira à pilhagem) a aprimorar os meios (efetivamente ocupar a região e se transferir a ela), também a afabilidade do trato cotidiano típica do brasileiro disfarçaria a maior violência do homem cordial: a incapacidade de distinção entre o público e o privado. Sérgio Buarque de Holanda entende o adjetivo cordial como relativo ao coração, ou mais precisamente aos interesses privados. Assim, os vasos que ligariam o brasileiro a seu colonizador português teriam como seiva bruta a alma do aventureiro cujo objetivo final seria enriquecer a si mesmo.

Nesse sentido, a afabilidade do brasileiro seria uma forma de esquivar-se do debate acirrado de ideias, seria uma estratégia para se manter alheio aos reveses, aos interesses individuais que o empenho em formar uma estrutura pública capaz de defender os direitos da maioria poderia demandar. Tal aspecto explicaria tanto os desmandos dos donos dos engenhos, cujo poder fundava-se em seus próprios interesses e no compadrio, instituindo o poder paralelo a um poder público inexistente, quanto a política brasileira, já no contexto urbano, das trocas de favores e da hedionda indistinção entre o público e o privado.

Avesso a qualquer autoridade que the pudesse alijar das vantagens de satisfazer seus próprios interesses, o homem cordial utilizaria a cortesia como máscara para evitar a adesão à autoridade constituída ou a um ritual rígido contrário a seus interesses. Se no campo da política, tal característica se relacionaria ao cumprimento das leis, no campo da religião, ao abrandamento dos rituais e uma 
aproximação quase familiar às entidades. No campo intelectual, a apropriação crítica a teorias seria substituída pela aceitação dos aspectos superficiais a doutrinas (Sérgio Buarque de Holanda menciona, por exemplo, a grande popularidade das fórmulas positivistas entre os pensadores brasileiros do final do século XIX, início do XX); no campo da literatura, paralelamente, a tendência à retórica retumbante, a cópia de tendências estrangeiras seriam também provas do apreço do homem cordial à superficialidade.

A categoria de análise, não só da poesia, mas do próprio caráter da figura do poeta que a desempenha, parece revelar valorização do trabalho poético que se opõe ao superficialismo, ou em outra chave, à polidez de aparências, um dos traços do "homem cordial". No quinto capítulo da primeira edição de Raízes do Brasil, Sérgio Buarque afirma que a atitude polida consistiria "precisamente em uma espécie de mímica deliberada de manifestações que são espontâneas no "homem cordial": "é a forma natural e viva, que se converteu em fórmula" (Holanda, 1936, p.102). Essa conversão de forma em fórmula, além de já tratada nos textos da década de 1920, parece um problema anunciado por Mário de Andrade nas páginas da coluna "Vida Literária" quando se refere à suposta perda de sinceridade da poesia parnasiana:

Seria simplesmente coxo intelectual quem imaginasse que eu esteja pregando qualquer volta ao formalismo parnasiano. O Parnasianismo foi muito frágil exatamente pela sua confusão entre forma e fôrma. Destruíram a fluidez da palavra que virou puro valor martelado e silábico. (Andrade, 1955, p.104)

No sexto capítulo da primeira edição de Raizes do Brasil, "Novos tempos", Sérgio Buarque atribui a aversão às atividades "morosas e monótonas", da criação estética às artes servis, à incapacidade do brasileiro de "aplicar-se de corpo e alma a um objeto exterior" a si mesmo. O trabalho estético e intelectual seria substituído pela facilidade em se alimentar, ao mesmo tempo,

[...] de doutrinas dos mais variados matizes e com que sustentam, simultaneamente, as convicções mais díspares. Basta que tais doutrinas e convicções se possam impor à imaginação por uma roupagem vistosa - palavras bonitas ou argumentos sedutores. (Holanda, 1936, p.113-4)

Esse não seria o caso de Manuel Bandeira, pois o ecletismo do autor não estaria relacionado à aceitação de padrões externos "díspares" e a falta de afetação nas descrições da natureza, nos termos do artigo, também o salvariam da tentação da roupagem vistosa. Para Sérgio Buarque, por esse motivo, a poesia de Bandeira não teria seduzido instantaneamente o leitor brasileiro, aliás a poesia dele encontraria afinidade com a vertente do simbolismo francês que justamente não teria se tornado mais aceita no Brasil:

Não é a riqueza verbal, a profusão lírica, a prestidigitação, o pitoresco, as imagens raras o que mais o seduz entre os simbolistas. Nem é a simples procura de ritmos novos e revolucionários, pois apesar de ter sido ele quem 
primeiro entre nós empregou o verdadeiro verso livre, não se tornou necessário o abandono dos ritmos tradicionais para que nos desse algumas de suas criações poéticas mais audaciosas. (Holanda, 1996a, p.277)

O autor de Libertinagem se afastaria do "homem cordial" à medida que o cultivo pessoal da técnica evitava um pastiche exuberante e, de certa forma, encontrava afinidades mais sinceras que simplesmente adaptar a poesia à aceitação do público. Ora, se o poeta se dedica à atividade morosa do cultivo técnico, ao mesmo tempo, parece ainda aplicado ao desenvolvimento da personalidade individual. A dimensão poética ganha, portanto, complexidade, pois, levando o julgamento ao extremo, o processo de aferição da técnica deve ser experimentado individualmente. Assim, o resultado final, ou seja, o poema pronto, por mais singular que possa parecer, não foi o objetivo exclusivo ou principal, mas o resultado de um processo artístico.

Raciocinando ainda a partir das categorias de Raizes do Brasil em relação aos modelos de colonizador que vieram às Américas, Manuel Bandeira estaria mais do lado do "trabalhador", mas também tangencia em certo ponto, por sua individualidade ímpar, o "aventureiro". 9 Se o homem ibérico, "personagem fantástico da imaginação buarqueana”, ${ }^{10}$ que está nas "raízes do homem cordial”, não conseguiria se entregar ao trabalho com objetivo fora das preocupações consigo mesmo, Manuel Bandeira parece superar esse comportamento, mas de maneira singular.

Em Manuel Bandeira, o homem não cordial, Sérgio Buarque assinala a simultaneidade da adesão ao trabalho técnico, que leva ao sacrifício de desenvolver uma obra que, pela grande marca pessoal, seja expressão de um poeta solitário sem ambições de agradar o público. Nesse ponto, é como se a própria raiz personalista, inegável em um poeta brasileiro como Bandeira, pudesse coexistir com um traço que a exclui, fundindo um elemento novo, mas ambíguo. Talvez essa fosse, na imaginação de Sérgio Buarque de Holanda, a fagulha possível para inflamar a "nossa revolução", pois afastaria a poesia brasileira de uma suposta superficialidade.

Em “Belo, forte e jovem”, texto publicado um ano antes do de Sérgio Buarque, Mário de Andrade (1955, p.15-19) reconhece a originalidade do estilo inimitável de Manuel Bandeira, com o qual muitos teriam procurado se afinar, ao afirmar que, em alguns momentos, a poesia de Vinícius de Moraes se aproximaria perigosamente da de Manuel Bandeira, sobretudo pelo uso de alguns preciosismos linguísticos e prosódia portuguesa, essa última característica que parece se aproximar da ideia de um passado ibérico. O crítico chamava a atenção, por exemplo, para trechos que se diriam escritos por Manuel Bandeira, como a primeira estância de "Amor nos três pavimentos", imitação "da mais dolorosa invenção" de A estrela da manhã.

Se, no artigo de 1939, a advertência a Vinícius de Moraes enfatiza a originalidade inimitável de Manuel Bandeira; um traço levantado por Sérgio Bu- 
arque, ou seja, o domínio da técnica do verso, que possibilitaria a Bandeira a versátil utilização tanto do verso livre quanto de métricas variadas, também fora notada por Mário de Andrade no artigo publicado da Revista do Brasil já em 1924. Para o autor de Panliceia desvairada, mesmo utilizando uma profusão de métricas, Bandeira "jamais foi artífice" (Andrade, 1924, p.222), sempre fora, portanto, "artista".

A diferença entre artista e artesão é o cerne do artigo "O artista e o artesão", aula inaugural do curso de Filosofia e História da Arte que Mário de Andrade lecionara no Rio de Janeiro, na Universidade do Distrito Federal. O professor afirma que a sinceridade artística teria três componentes básicos: o treino artesanal, o conhecimento técnico de uma arte (e por que não, para o crítico, o estudo da literatura, da crítica, da história), e o traço individual que seria treinar e tentar expressar a fatalidade de cada um. Mais uma vez, o crítico se levantará contra aqueles que julga seguir interesses de mercado ou sabotar a própria arte não treinando e copiando procedimentos.

Se para ser artista é necessário domínio da técnica pessoal, o julgamento de Mário de Andrade se aproxima ao de Sérgio Buarque, pois, para este a sinceridade da conquista do domínio técnico, relacionada diretamente ao desenvolvimento da expressão singular, levaria à manifestação de um "lirismo" proveniente "de fontes misteriosas e íntimas, exigindo para realizar-se condições especiais que não se podem forjar arbitrariamente" (Holanda, 1996a, p.277).

O caminho rumo ao encontro da técnica pessoal já havia sido adiantado por Mário de Andrade no artigo de 1924:

O defeito subsiste porém. Mas na obra dos verdadeiros poetas os defeitos têm tanto interesse como as qualidades. São muitas vezes característicos e um verdadeiro elemento de grandeza até. O que é preciso é classificar os defeitos. Há os que vêm da precariedade técnica ou intelectual. Há os que provêm da abundância lírica ou da psicologia do criador. Estes penso que até devem ser desenvolvidos. Aqueles depreciam a obra de arte. (Andrade, 1924, p.222)

No caso de Manuel Bandeira, o "defeito" seria proveniente da "abundância lírica" e da "psicologia do criador". Apesar da reprimenda à proximidade com Manuel Bandeira em "Belo, forte e jovem", Mário de Andrade afirma que o livro Novos poemas, de Vinícius de Moraes, seria irregular, pois nele estariam "os piores e os melhores versos do poeta" (Andrade, 1955, p.15) e esse aspecto seria também marca de sinceridade no desenvolvimento de uma técnica pessoal. Assim, a firmeza de estilo dos livros anteriores de Vinícius de Moraes teria desaparecido. Isso seria positivo, pois essa firmeza não seria proveniente de uma personalidade definida, mas de seguir uma "doutrina estética" (ibidem, p.15) tributária de opiniões alheias, como as de Otávio de Faria.

Observando o exemplar (Moraes, 1938) de Novos poemas anotado por Mário de Andrade, é possível verificar notas marginais que, ao longo das páginas, 
vão asseverando a preocupação do crítico e testemunhando mesmo a própria gênese do artigo. Se no poema "Ternura" há a anotação "Alta poesia serena", ao lado do "Invocação à mulher única", Mário de Andrade escreve "Infantilismo". Essa intermitência na qualidade dos poemas representaria "autocrítica" positiva, pois revelaria um poeta em busca do domínio da técnica literária.

A busca por uma "personalidade literária" própria teria levado Vinícius de Moraes a novos caminhos, como a já mencionada apropriação da poética de Manuel Bandeira, que teria dado aos poemas "um sopro novo de vida real e de maior objetividade". Para Mário de Andrade, essa nova afinidade, apesar de benéfica, também teria levado o poeta, em alguns casos, a uma imitação excessiva. Para exemplificar sua opinião, indica uma forte semelhança entre a primeira estrofe de "Amor nos três pavimentos" e "Estrela da manhã" de Bandeira. Também nesse momento, pode-se notar que o comentário partiu de uma anotação, no exemplar de trabalho, na qual, ao lado da mesma primeira estrofe, está escrito "Manuel Bandeira". Além disso, ao lado do poema "Balada para Maria", Mário de Andrade também anota "Manuel Bandeira", observação que transporá para a crítica com a afirmação: "Também na 'Balada para Maria' há trecho que se diriam escritos por Manuel Bandeira" (Andrade, 1955, p.17). Na última estrofe desse poema, anota ainda "Mau gosto", o que foi transformado, no decorrer no artigo, em "brincadeira sem o menor interesse essencial" (ibidem, p.19), indicando a necessidade do crítico de integrar os comentários à estrutura do texto.

A noção de sinceridade nos dois críticos se aproxima devido à importância dada ao processo de experimentação formal. Antonio Arnoni Prado aponta, em comentário preciso, como um dos mais importantes vínculos entre Mário de Andrade e Sérgio Buarque de Holanda, justamente a constatação de que

[...] a tarefa de compreender o lirismo absoluto significa compreender de que modo ele é atingido primeiro em virtude do aprimoramento técnico do artista, levando em conta - na lição de Mário, absorvida por Sérgio - que "todas as leis técnicas e intelectuais só apareçam pelas próprias razões da libertação, e nunca como normas preestabelecidas". (Prado, 2015, p.187)

Para Mário de Andrade, a busca da técnica pessoal corresponde à honestidade do artista e, nesse sentido, o trabalho artesanal admitiria também elaborações poéticas com problemas. Nesse caso, a busca da sinceridade como critério artístico ao mesmo tempo que visa buscar constância da "pesquisa estética", parece justificar também a imagem de Mário de Andrade, cuja preocupação em assumir e justificar sua própria obra literária, que considera prejudicada pela "militância modernista”, é constante nos momentos de seu ensaísmo. Para Sérgio Buarque de Holanda, a imagem de Manuel Bandeira parece estar nas antípodas a um dos aspectos importantes do "homem cordial": o apreço à superficialidade da adesão a teorias vindas de fora. Nesse caso também a sinceridade artística da pesquisa poética é que constituiria o valor do poeta. No juízo dos críticos parece submergir a imagem de dois intelectuais, cuja sinceridade maior talvez 
não esteja exatamente na crítica enviesada dos momentos das disputas dentro do território literário brasileiro, mas no próprio ato de pesquisa poética, o que parece também compor, nesse caso, uma retórica da sinceridade que remete ao escritor artesão e ao intelectual pesquisador.

\section{Notas}

1 Este artigo é resultado de pesquisa financiada pela Fundação de Apoio à Pesquisa do Estado de São Paulo (Fapesp), cujo apoio este pesquisador agradece.

2 Em carta, de 9.61942 a Murilo Miranda, Mário comenta a exclusão do artigo de Manuel Bandeira: “[Manuel Bandeira] Releu o artigo e argumentou violento quando estive aí [Rio de Janeiro], que não! que eu não podia tirar o ensaio e deu as razões. Algumas plausíveis, certas observações críticas que fui o primeiro ou único a revelar a ele sobre si mesmo. Mas não interessa argumentar. O sacrifício aí é puramente de valor meu pessoal, porque o artigo é detestável como espírito de concepção e estilo. Mas não quero dar um descontentamento ao Manuel e me sacrifico gostoso" (Andrade, 1981, p.113).

3 Em junho de 1921, Mário de Andrade publicou, no Jornal do Commercio, artigo em que refutava a denominação de "futurista" dada por Oswald de Andrade, ora questionando a filiação estética em relação ao futurismo, ora construindo uma imagem social incompatível com a de um iconoclasta vanguardista (cf. Brito, 1997, p.230-4).

4 Não apenas para Benjamin Crémieux, a noção de sinceridade era incompatível. Nas primeiras décadas do século XX, a relação sincera entre autor e persona foi algumas vezes questionada, como lembra Trilling. Para os surrealistas, a expressão lírica sincera seria aquela, por exemplo, que emanaria do inconsciente e não da confluência persona e autor; para T.S. Eliot, corresponderia à busca da técnica. Para ele, "o progresso de um artista" seria "um contínuo sacrífico de si mesmo, uma contínua extinção da personalidade" (Eliot, 1921, p.7).

5 Raciocínio, aliás, já presente no "Prefácio interessantíssimo", de Mário de Andrade: "Dom Lirismo, ao desembarcar do Eldorado do Inconsciente no cais da terra do Consciente, é inspecionado pela visita médica, a Inteligência que o alimpa dos macaquinhos e de toda e qualquer doença que possa espalhar confusão, obscuridade na terrinha progressista. Dom Lirismo sofre mais uma visita alfandegária, descoberta por Freud, que a denominou Censura. Sou contrabandista! E contrário à lei da vacina obrigatória” (Andrade, 2013, p.72).

6 Sobre esse assunto, conferir Moraes (2013).

7 Nessa carta, de 1942, a moral do artista está relacionada a também uma questão explicitamente política.

8 Em "Raízes do Brasil e o modernismo" (Prado, 2004, p.263-70) e "No roteiro de Raízes" (Prado, 2006, p.295-312), Antonio Arnoni Prado trata dos possíveis diálogos entre Raizes do Brasil e o a crítica literária de Sérgio Buarque de Holanda.

9 O aventureiro desejaria conquistar o mundo sem o esforço do cultivo, ambicioso, transformaria obstáculo em trampolim, enxergando primeiro o triunfo a alcançar. $\mathrm{O}$ trabalhador enxergaria, antes do triunfo, a dificuldade a vencer, valorizando mais a parte que o todo: "Existe uma ética do trabalho, como existe uma ética da aventura. 
Assim, o indivíduo do tipo trabalhador só atribuirá um valor moral positivo às ações que sente ânimo de praticar e, inversamente, terá por imorais e detestáveis as qualidades próprias do aventureiro, a audácia, a imprevidência, a irresponsabilidade... e tudo quanto se relacione com a concepção espaçosa do mundo, característico desse tipo" (Holanda, 1936, p.21).

10 A expressão é de Pedro Meira Monteiro (1999, p.325) no artigo "Buscando a América".. Para o autor, no homem ibérico, "a entrega individual não é a capitulação metódica ao trabalho perseverante de prostrar-se diante de uma verdade superior que, encarnada num projeto ou numa pessoa, possa revelar-se neste mesmo plano em que vivemos, oferecendo um alívio definitivo a todos os nossos males" (ibidem).

\section{Referências}

ANDRADE, M. de. Luzes e refrações. Klaxon. São Paulo: n.1, p.15-16, 15 maio 1922.

23, nov. 1924.

Manuel Bandeira. Revista do Brasil, São Paulo, ano IX, v.XXVI, n.107, p.214. O empalhador de passarinho. 2.ed. São Paulo: Martins, 1955.

. Cartas de Mário de Andrade a Murilo Miranda. Rio de Janeiro: Nova Fronteira, 1981 .

. Vida literária. Pesquisa, estabelecimento de texto, introdução e notas de Sonia Sachs. São Paulo: Hucitec; Edusp, 1993.

. Poesias completas. v.I. Edição de Tatiana Longo e Telê Ancona Lopez. Rio de Janeiro: Nova Fronteira, 2013.

BRITO, M. da S. História do modernismo brasileiro: antecedentes da Semana de Arte Moderna. 6.ed. Rio de Janeiro: Civilização Brasileira, 1997.

ELIOT, T. S. The sacred wood: essays on poetry and criticism. New York: Alfred A. Knopf, 1921.

HOLANDA, S. B. de. Raizes do Brasil. Rio de Janeiro: José Olympio, 1936.

1996a. v.1.

O espirito e a letra. Org. Antonio Arnoni Prado. São Paulo: Cia. das Letras, 1996b. v.2.

O espirito e a letra. Org. Antonio Arnoni Prado. São Paulo: Cia. das Letras,

MONTEIRO, P. M. A queda do aventureiro: aventura, cordialidade e os novos tempos em Raízes do Brasil. Campinas: Ed. da Unicamp, 1999.

MORAES NETO, P. Sobre a sinceridade. Estética, ano II, v.I, p.157-64, jan.-mar. 1925.

MORAES, M. A. de. (Org.) Correspondência Mário de Andrade \& Manuel Bandeira. 2.ed. São Paulo: Edusp; IEB, 2001.

MORAES, R. G. O aviador e a florista: intersecções entre o crítico de poesia e o professor Mário de Andrade. Manuscritica, n.25, p.31-44, 2013.

MORAES, V. de. Novos poemas. Rio de Janeiro: José Olympio, 1938.

PRADO, A. A. Trincheira palco e letras. São Paulo: Cosac \& Naify, 2004. 
PRADO, A. A. No roteiro de Raizes. in: ARAÚJO, R. B.; SCHWARZC, L. M. Raizes do Brasil-Edição Comemorativa 70 anos. São Paulo: Cia. das Letras, 2006. p.295-312.

Um diálogo que volta: Mário de Andrade e Sérgio Buarque. In: Cenário com retratos: esboços e perfis. São Paulo: Cia. das Letras, 2015. p.175-89.

ROSENBAUM, S. B. Professing sincerity: modern lyric poetry, comercial culture, and the crisis in reading. Charlottesville: University of Virginia Press, 2007.

TRILLING, L. Sinceridade e autenticidade. São Paulo: É Realizações, 2014.

RESUMO - A poesia de Manuel Bandeira, um dos mais profícuos poetas brasileiros do século XX, interessou tanto à crítica literária de Mário de Andrade quanto à de Sérgio Buarque de Holanda. O objetivo deste artigo é analisar os critérios que sustentam as críticas de Mário de Andrade e Sérgio Buarque à poesia de Manuel Bandeira, tendo como ponto de partida a afirmação da trajetória artística sincera do poeta. No caso de Mário de Andrade, tal conceito parece retomar as reflexões sobre a técnica da poesia desenvolvidas sistematicamente em "O artista e o artesão"; no caso de Sérgio Buarque, parece figurar como um dos combustíveis para a revolução contra a "cordialidade" brasileira, conforme definida em Raizes do Brasil.

PALAVRAS-CHAVE: Modernismo brasileiro, Crítica Literária, Mário de Andrade, Sérgio Buarque de Holanda, Sinceridade.

ABSTRACT - The poetry of Manuel Bandeira, one of the most prolific Brazilian poets of the twentieth century, drew the attention of the literary criticism of both Mário de Andrade and Sérgio Buarque de Holanda. The aim of this article is to analyze the criteria that support the critical approaches of Andrade and Holanda to the poetry of Manuel Bandeira, using as a starting point the poet's sincere artistic trajectory. In the case of Mário de Andrade, this concept seems to reconsider the reflections on the technique of poetry developed systematically in "O artista e o artesão". In the case of Sérgio Buarque, the concept seems to figure as one of the fuels of the revolution against Brazilian "cordiality", as defined in Roots of Brazil.

KEYWORDS: Brazilian Modernism, Literary criticism, Mário de Andrade, Sérgio Buarque de Holanda, Sincerity.

Ricardo Gaiotto de Moraes é docente permanente do Programa de Mestrado em Linguagens, Mídia e Artes, e da Faculdade de Letras, na Pontifícia Universidade Católica de Campinas. Doutor e mestre em Teoria e História Literária, com licenciatura e bacharelado em Letras, pela Universidade Estadual de Campinas. @ - rgaiotto@gmail.com

Recebido em 20.6.2017 e aceito em 17.7.2017.

I Faculdade de Letras, Pontifícia Universidade Católica de Campinas, Campinas, São Paulo, Brasil. 